\title{
Incidence of metal sensitivity in patients with total joint replacements
}

\author{
$M$ W ELVES, J N WILSON, J T SCALES, H B S KEMP
}

British Medical fournal, 1975, 4, 376-378

\begin{abstract}
Summary
Sensitivity to chromium, cobalt, nickel, molybdenum, vanadium, and titanium was studied by patch tests in 50 patients who had received total joint replacements. Nineteen $(38 \%)$ were sensitive to one or more of the metals. In 23 patients non-traumatic failure of the prosthesis had occurred, and 15 of these patients were sensitive to metal. Out of 27 patients with no evidence of prosthesis loosening, four were sensitive to nickel and cobalt or nickel only. Dermatological reactions occurred in 13 patients after surgery; in only eight, however, was there evidence of metal sensitivity. These findings indicate that metal-on-metal total joint replacements may sensitise the patient to metals contained in the prosthesis. Although there is a high incidence of prosthesis failure among metal-sensitive patients it remains uncertain whether the loosening causes the sensitisation or vice versa.
\end{abstract}

\section{Introduction}

There are several well established causes of the loosening of joint prostheses, such as infection, faulty implantation, trauma, and, in early types of prosthesis, design faults. Recently, however, the development of a state of immunological sensitivity to the metallic components of the joint replacement has been suggested as a further cause of loosening. It is well established that in vivo during the wear of metal-on-metal bearings of prostheses grey-staining particulate material is found in tissues. ${ }^{12}$ These particles have been shown by $x$-ray fluorescence spectroscopy to be metallic. ${ }^{3}$ In patients with metal-on-metal hip prostheses both cobalt and chromium can be detected, often in considerable quantities, in the blood, urine, and hair. ${ }^{4}$

Recently there have been several reports of patients suffering from urticarial or ezcematous dermatitis, which has been attributed to the presence of an implanted metallic prosthesis or other appliance. ${ }^{5-8}$ Patch tests showed these patients to be positive to nickel, and removal of the implant led to resolution of the dermatological condition. Evans et al carried out skin tests with solutions of nickel, cobalt, and chromium salts in 14 patients with loose metal-on-metal prostheses and found positive reactions in nine. ${ }^{1}$ No evidence of sensitivity was obtained in 24 patients with stable prostheses. We examined the sensitivity of patients with total joint replacements to nickel, cobalt, chromium, vanadium, molybdenum, and titanium. We report here the preliminary results of this survey.

\footnotetext{
Institute of Orthopaedics (University of London), and Royal National Orthopaedic Hospital, Brockley Hill, Stanmore

$M$ W ELVES, PHD, MIBIOL, senior lecturer in cell science

J N WILSON, CHM, FRCS, consultant orthopaedic surgeon

J T SCALES, FRCS, CIMECHE, professor of biomedical engineering

H B S KEMP, MS, FRCS ED, senior lecturer in orthopaedics and consultant orthopaedic surgeon
}

\section{Patients and methods}

The 50 patients studied were recipients of various types of total joint replacements (see table). They fell into two groups. Group 1 consisted of 36 unselected recipients of Stanmore metal-on-metal prostheses (some with bilateral hip replacements) and four unselected recipients of special femoral prostheses used to replace resected tumours. These patients included those whose prostheses had failed and those who had a good result. Group 2 consisted of 10 patients with a variety of prostheses who were investigated because of failure of the appliance. The prostheses in all these patients had been inserted from one to 12 years earlier.

Metal sensitivity tests-Patch tests were carried out using Al-test strips (Astra Chemicals), to the pads of which were applied the metal allergens. The strips were placed on the back and held in place with hypoallergic tape (Micropore). Allergens used were nickel sulphate $(5 \%)$, cobalt chloride $(2 \%)$, and potassium dichromate $(0.5 \%)$, each in white paraffin $(B P)$ (supplied by Trolle-Lassen Laboratories, Hellerup, Denmark). Potassium titanium oxalate $(1 \%)$, ammonium molybdate $(1 \%)$, and ammonium metavandate $(0.1 \%)$ were applied as solutions (supplied by AWRE, Aldermaston). Patches were removed after three days and the reactions were read and scored. All test sites were examined again on the seventh day. Scores were as follows: erythema + ; vesicular rash confined to area of patch ++ ; extensive eczematous reaction beyond area of patch +++ . Occasional follicular reactions were observed in tests with cobalt. ${ }^{9}$ These were, however. not reproducible and were not regarded as significant.

At the time of patch testing a history was taken from each patient with particular emphasis on reaction to contact with metals or metal salts.

Correlation between metal sensitivity and type of prosthesis

\begin{tabular}{|c|c|c|c|c|c|}
\hline Type of prosthesis & $\begin{array}{c}\text { No of } \\
\text { patients }\end{array}$ & $\underset{\text { sensitive }}{\text { No }}$ & $\begin{array}{c}\text { No } \\
\text { failed and } \\
\text { sensitive }\end{array}$ & $\begin{array}{l}\text { No failed } \\
\text { and not } \\
\text { sensitised }\end{array}$ & $\begin{array}{l}\text { No } \\
\text { stable and } \\
\text { sensitised }\end{array}$ \\
\hline \multicolumn{6}{|c|}{ Group 1 unilateral } \\
\hline \multirow{4}{*}{$\begin{array}{l}\text { Stanmore Mk I or II } \\
\text { Stanmore Mk III } \\
\text { Stanmore metal/plastic } \\
\text { Special Stanmore } \\
\text { femoral prosthesis }\end{array}$} & 8 & 6 & 5 & 0 & \\
\hline & 12 & 4 & $\begin{array}{l}2 \\
0\end{array}$ & 18 & $\begin{array}{l}2 \\
0\end{array}$ \\
\hline & 4 & 0 & 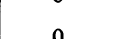 & 18 & 0 \\
\hline & \multicolumn{5}{|c|}{ Group 1 bilateral } \\
\hline \multirow{4}{*}{$\begin{array}{l}\text { Both Stanmore } \\
\text { metal/metal } \\
\text { Both Stanmore } \\
\text { metal/plastic } \\
\text { Stanmore metal/metal, } \\
\text { metal/plastic }\end{array}$} & & & & & \\
\hline & 4 & 1 & $1 \dagger$ & $1 t$ & 0 \\
\hline & 2 & 1 & $1 \dagger$ & 0 & 0 \\
\hline & 8 & 2 & $1 \ddagger$ & $3(1 \S)$ & 1 \\
\hline \multirow{6}{*}{$\begin{array}{l}\text { McKee/Farrar } \\
\text { Hip and knee } \\
\text { Bilatera! knees } \\
\text { (Freeman-Swanson) } \\
\text { Stanmore elbow } \\
\text { Stanmore hinged knee }\end{array}$} & & Group 2 & & & \\
\hline & 5 & 2 & 2 & 3 & 0 \\
\hline & 2 & 1 & $1^{*}$ & 1 & 0 \\
\hline & 1 & 1 & $1 \pm$ & 0 & 0 \\
\hline & 1 & 1 & 1 & 0 & 0 \\
\hline & $1^{*}$ & 0 & 0 & 0 & $\mathbf{0}$ \\
\hline
\end{tabular}

*Severe eczematous reaction; prostheses were sound.

†Bilateral failure.

\$Fractured prosthesis or trauma.

\section{Results}

Of the 50 patients tested 19 gave positive reactions-2 to nickel only, 8 to cobalt, 6 to both cobalt and nickel, 1 to both nickel and vanadium, and two to chromium. Thus the overall incidence of metal sensitivity in these patients was $38.0 \%$

The prostheses of 26 patients had failed: in 10 patients the prostheses had loosened and had been removed; in 4 they had loosened but had not been removed, in 2 they were firm but there was severe skin reaction, in 3 trauma had caused fracture, in 1 there was capsular swelling, in 1 there was severe pain but no evidence of loosening, and in 5 patients with two prostheses one prosthesis had failed and the other achieved a good result.

When the results of the metal sensitivity tests were correlated with 
the fate of the prosthesis there were 15 metal-sensitive patients among the 26 patients whose prostheses had failed. Three of these prostheses failed, however, because of fracture of the appliance as a result of trauma, and when these were excluded the incidence of sensitisation in the remaining 23 patients with failed prostheses was $65.2 \%$. Evidence of infection was found when the prostheses were removed in four patients, only one of whom had a metal sensitivity. Thus the incidence of sensitivity to metals in unexplained loosening was higher $(73.7 \%)$. The incidence of sensitivity and failure with the different types of prosthesis is summarised in the table.

In 14 patients bilateral Stanmore total hip replacements had been inserted. In only one case was metal sensitivity found in a patient with a unilateral failure. A further three patients had received either bilateral knee replacements (1) or a hip and a knee replacement (2). In only the former case was there evidence of cobalt sensitivity, and bone resorption was radiologically obvious at the prosthesis bone interface in one knee but not yet in the other. One patient with hip and knee prostheses was sensitive to nickel and the knee had to be amputated because of an eczematous reaction around the wound site that became infected. The prosthesis itself, however, was firmly in place, and the metal-on-plastic hip replacement remained functionally satisfactory. Four patients who received special Stanmore metal-onmetal prostheses for the hip and upper femur showed no evidence of sensitisation. These patients required prosthetic replacement after excision of a tumour; they did not, therefore, have degenerative joint disease and were also younger than patients receiving total hip replacements for osteoarthritis.

Of the 24 patients who had stable prostheses only four were positive for nickel and cobalt (3) or cobalt alone (1). Two gave a positive history of metal contact sensitivity. When the three patients whose appliances failed due to trauma were added to this group the incidence of sensitivity to metals in patients with non-loosened prostheses was $14 \cdot 8 \%$.

Dermatitis occurred after the operation in 13 patients, of whom eight were later found to be sensitive to metal salts. In only two patients was this reaction problematical, however: in one it took some months to resolve and in the other secondary infection occurred, which led to amputation. Dermatitis in the others lasted for only a few days and in most cases required no treatment. The onset of the skin reaction varied from one to two weeks to 24 months after operation. Three of these 13 patients gave a history of metal sensitivity.

\section{Discussion}

Our results confirm those of Evans et $a l^{1}$ in showing a significantly increased incidence of metal sensitivity in patients who have received metallic total joint replacements. Like Evans et al, we also found a high incidence of sensitivity to cobalt. Data on the incidence of metal sensitivity are not yet available for age- and sex-matched subjects without implanted metal, but the incidence of cobalt sensitivity among people attending contact dermatitis clinics is low (about $1.5 \%$ ). ${ }^{1011}$ This observation may be of importance in deciding whether there is a causal link between the presence of the prosthesis and the state of sensitivity. There have been no prospective studies to throw light on this problem, but the fact that the incidence of cobalt sensitivity in both our study $(28 \%)$ and that of Evans et al $(21 \%)$ was more than 10 times that reported in other populations strongly suggests that the sensitivity to this metal develops as a result of the wear of the prosthesis. An alternative hypothesis would be that people with a tendency to develop metal sensitivity also have a higher susceptibility to degenerative joint disease. None of the patients sensitive to cobalt alone had a history of metal sensitivity. In contrast, six of the nine nickel-sensitive patients and one of two chromiumsensitive patients had a previous history of dermatitis on contact with metal.

It is difficult to assess the relation between the immunological sensitivity and the loosening of the prosthesis. The latter may be either the cause of the former or the result. This question can only be definitely resolved by means of serial examination of patients receiving total joint prostheses to determine which comes first. We are now undertaking such a study. We found that the highest rate of failure associated with metal sensitivity occurred in patients receiving Stanmore Mk I or II metal-on- metal hip joints which had a horseshoe-shaped bearing. ${ }^{12}$ These appliances were prone to seizing up and had a high wear rate. It is interesting to note, however, that the two recipients of $\mathrm{Mk}$ I or II cups that did not loosen did not develop metal sensitivity. On the other hand, Stanmore joints with the Mk III type acetabular cup, which has an apical bearing, had a low failure rate ( 3 out of 12), and in two cases failure was associated with metal sensitivity. No Mk IV cups-the current designwere examined nor have any clinical complications been noted in recipients. Four patients with evidence of metal sensitivity had at the time of writing, shown no signs of failure; their prostheses were inserted three and a half to six years ago.

Metal-on-plastic joint replacements generate considerably smaller amounts of metallic wear products, ${ }^{413}$ so metal sensitivity should be less common with this type of prosthesis. In our study we examined four patients with metal-on-plastic hip joints and one patient with bilateral metal-on-plastic (FreemanSwanson) knee joints. Metal sensitivity to cobalt was detected in the latter and in one of the former patients. Similarly, Evans et al reported one patient who was sensitive to cobalt and who had received Freeman-Swanson knee joints ${ }^{1}$; their patient, however, had previously received metal-on-bone MacIntosh arthroplasties. It was not possible to decide whether the state of sensitivity was due to the arthroplasty or whether it was induced by the metal-on-plastic knee prosthesis. Thus it seems that metal-on-plastic prostheses may also be associated with metal sensitivity, but the incidence relative to metal-on-metal joint replacements will have to be determined by studying more patients with metal-on-plastic joints. Such a study is in progress.

The development of dermatological reactions in patients who have undergone joint replacement requires some comment. Others have reported dermatological conditions developing in patients with metal implants who were also sensitive to nickel. ${ }^{5-8}$ Thirteen of our patients developed an erythemic or eczematous rash after operation; the site of the rash varied but in most cases the rash affected skin adjacent to the operation site or on the feet. In eight of these patients there was evidence of metal sensitivity when they were patch tested some time later, and three of these gave a positive history of metal sensitivity before operation. In most cases the rash resolved within a few days though occasionally it was present for several weeks and required topical steroid treatment. In one patient the skin lesion became infected and led to the amputation of the limb. None of these patients had flare-up reactions on patch testing. In the series reported by Evans et al there was no mention of postoperative skin reaction. ${ }^{1}$ The occurrence of dermatological reactions after prosthetic surgery may suggest metal sensitivity, but it cannot be regarded as a reliable indication of the sensitised state. Almost a third of our patients who developed a rash had no evidence of metal sensitivity.

A final point for discussion is the relevance of sensitivity on a patch test to the condition of the deeper tissues around the prosthesis. Evans et al speculated that release of metal from prostheses by wear causes tissue sensitisation and, ultimately, obliterative changes in blood vessels supplying bone. ${ }^{1}$ Thus death of bone occurs and "the integrity of the bone/prosthesis bond is prejudiced." There is, however, no direct evidence that this is the case. That the metal sensitivity can involve deep tissues cannot be doubted as there is evidence that the sensitivity is due to a cell-mediated immune response. Thus lymphocytes from patients with nickel sensitivity have been shown under certain conditions to undergo blastic transformation in vitro in the presence of nickel salts. ${ }^{14-18}$ Similar transformation has been shown in the case of chromium sensitivity. ${ }^{1920}$ Lymphocyte transformation in cultures containing nickel can be shown in patients with metal-on-metal prostheses who give a positive patch test result and also, to a lesser extent, in patients with a prosthesis but a negative patch test result. ${ }^{21}$ Lymphocytes stimulated by nickel also produce macrophage migration inhibition factors in vitro. ${ }^{18}$ In animal studies Polak et al have shown cell-mediated immunity in guinea-pigs immunised with chromium salts. ${ }^{22}$ 
It has been suggested that chromium compounds do not act as immunogens themselves but act by denaturing autologous protein, rendering them autoantigenic. ${ }^{23}$ This view has, however, been disputed and an alternative suggestion is that the chromium acts as a haptene and forms a conjugate with protein. ${ }^{22}$ A similar haptene-like mechanism has been suggested in the case of nickel sensitivity. ${ }^{24}$ Such an event may occur in the tissues around the prosthesis. The mechanism by means of which the cell-mediated immune response causes loosening at the prosthesis/bone interface is unknown and must be the subject of further study.

In conclusion, there is now evidence that metal-on-metal total joint replacements do sensitise the patient to metals contained in the prosthesis. Sensitisation seems to be correlated with the wear characteristics of the prosthesis, and the incidence of metal sensitivity is greatest in recipients of joints with a high wear rate. Although there is a high incidence of failure of prostheses among patients with metal sensitivity it would be premature to ascribe the former to the latter with any degree of certainty. A question which clearly needs to be resolved is whether the loosening occurs before the sensitisation to metal or whether it follows it. Further studies are in progress which we hope will resolve this problem and also throw some light on the mechanism of loosening in the presence of an immunological response.

We acknowledge the help given in the organisation of this investigation by Miss Joyce Bradley, deputy medical records officer, Royal National Orthopaedic Hospital; and Miss Jane Cotterill, who also helped with the preparation of the manuscript. We thank our colleagues on the staff of the Royal National Orthopaedic Hospital for allowing us to study patients under their care.

\section{References}

${ }^{1}$ Evans, E M, et al, Fournal of Bone and Foint Surgery, 1974, 56B, 626.

2 Scales, J T, and Lowe, B A, in Total Hip Replacement, ed M Jayson. London, Sector Publishers, 1974.

${ }^{3}$ Winter, G D, in Materials for Use in Medicine and Biology, ed D F Williams. London, Sector Publishers, 1974.

${ }^{4}$ Coleman, R F, Harrington, J, and Scales, J T, British Medical fournal, $1973,1,527$.

${ }^{5}$ McKenzie, A W, Aitken, C V, and Ridsdill-Smith R, British Medical fournal, 1967, 4, 36.

${ }^{6}$ Symeonides, P P, Paschaloglou, C, and Papegeorgiou, S, fournal of Allergy and Clinical Immunology, 1973, 51, 251.

'Barranco, V P, and Soloman, $\mathrm{H}$, Fournal of the American Medical Association, 1972, 220, 1244.

8 Pegum, J S, Lancet, 1974, 1, 674.

${ }^{9}$ Fisher, A A, Contact Dermatitis, 2nd edn. Philadelphia, Lea and Febiger, 1973.

${ }^{10}$ Fregert, S, and Rorsman, H, Acta Dermato-Venerologica, 1966, 46, 144.

${ }^{11}$ Ashman, D M, personal communication, 1975.

12 Wilson, J N, and Scales, J T, Clinical Orthopaedics, 1973, 95, 239.

${ }^{13}$ Swanson, S A V, Freeman, M A R, and Heath, J C, fournal of Bone and foint Surgery, 1973, 55B, 759.

${ }^{14}$ Gimenez-Camarosa, J M, et al, British fournal of Dermatology, 1975, $92,9$.

${ }^{15}$ MacLeod, T M, Hutchinson, F, and Raffle, E J, British fournal of Dermatology, 1970, 82, 487.

${ }^{16}$ Hutchinson, F, Raffle, E J, and MacLeod, T M, fournal of Investigative Dermatology, 1972, 58, 362.

${ }^{17}$ Pappas, A, Orfanos, C E, and Bertram, R, fournal of Investigative Dermatology, 1970, 55, 198.

${ }^{18}$ Forman, L, and Alexander, S, British fournal of Dermatology, 1972, 87, 320

19 Grosfeld, J C M, et al, Dermatologica (Basel), 1966, 132, 189.

20 Jung, E G, Therapeutisch Umschau, 1969, 26, 94.

21 Elves, M W, unpublished observation, 1975.

22 Polak, L, Turk, J L, and Frey, J R, Progress in Allergy, 1973, 17, 145.

${ }_{23}$ Pautrizel, R, Rivasseau, J, and Rivasseau-Coutant, A, Médicine et Hygiène, $1962,533,47$

${ }^{24}$ Jansen, L H, Berreus, L, and Van Delden, J, Dermatologica (Basel), 1964 128,491 .

\title{
Acute cardiomyopathy with rhabdomyolysis in chronic alcoholism
}

\author{
BASIL I B SENEVIRATNE
}

British Medical fournal, 1975, 4, 378-380

\section{Summary}

Of five chronic alcoholics with acute skeletal muscle necrosis (rhabdomyolysis) three developed acute heart failure with disturbances of rhythm and conduction. Symptoms came on abruptly after a period of intensified drinking. Myocardial infarction, thiamine deficiency, and cobalt intoxication were excluded. Probably the whole spectrum of muscle disease in chronic alcoholism may be commoner than has been suspected.

\section{Introduction}

Hed et $a l^{12}$ described an acute muscular syndrome in chronic alcoholics characterised by aching, tenderness, and oedema in the muscles and subcutaneous tissues; muscle necrosis (rhabdomyolysis); increased levels of creatinine phosphokinase

Southland Hospital, Invercargill, New Zealand BASIL I B SENEVIRATNE, MD, MRCP, physician
(CPK), serum transaminases (SGOT and SGPT), and lactate dehydrogenase (LDH); and myoglobinuria. The leg muscles were commonly affected and the clinical picture usually resembled deep vein thrombosis. All were advanced alcoholics and the symptoms occurred after a period of exceptionally heavy drinking.

Since then a spectrum of muscle disorders in alcoholism has been recognised, which ranges from no muscle symptoms but biochemical evidence of muscle disease such as a raised $\mathrm{CPK}^{3}$ to an acute reversible syndrome with muscle cramps and tenderness with no muscle necrosis, ${ }^{4}$ chronic proximal myopathy, ${ }^{3}{ }^{56}$ and acute rhabdomyolysis as reported by European workers. Except for one solitary case ${ }^{7}$ there has been no previous report of the heart being affected in the acute syndrome, and the present report on five patients with rhabdomyloysis, three of whom had unequivocal evidence of acute cardiomyopathy, extends the spectrum.

\section{Case 1}

A man aged 44 had drunk 41 of beer a day for years. After a period of exceptionally heavy drinking he presented in October 1974 with dyspnoea, palpitations, and severe pains in the upper arms, calves, and lumbar region for two days and of acute onset. He had had intermittent painful cramps in the calves and thighs for three months.

On examination he was found to be afebrile, orthopnoeic, and extremely distressed by pain in the upper arms, thighs, and lumbar 